\title{
O PRECONCEITO NO USO DO LÉXICO
}

Alcebíades Fernandes Jr.*

\begin{abstract}
RESUMO: Fundamentado em uma pesquisa de campo, há nesse artigo uma amostra dos primeiros resultados concretos de uma investigação lexicológica e lexicográfica para uma reflexão interdisciplinar, aplicada em grupos sociais, com o objetivo de comprovar e elucidar a preconceituação no uso do léxico, a qual decorre de uma interferência na relação entre significante e significado. Em virtude do resultado apresentar unidades lexicais "ingênuas" do ponto de vista lexicológico e lexicográfico, o processo de preconceituação no uso do léxico é um fenômeno que tem princípios éticos na estrutura de relações sócio-culturais.
\end{abstract}

Palavras-chave: léxico, processo, preconceito.

Tendo em vista a proposta dos trabalhos "A Marginalização no Léxico" apresentado no XLI Seminário do GEL e publicado em XXIII Anais de Seminários do GEL e "Uma Pesquisa sobre a Marginalização no Léxico" apresentado no IX Encontro Nacional da ANPOLL, constatou-se a existência de preconceito no uso do léxico, através de uma pesquisa de campo aplicada a grupos sociais, utilizando um método adequado para a investigação íntima psico-lexicológica do indivíduo do grupo selecionado. Tal preconceito é tão verdadeiro que o uso do termo "marginalização" nos trabalhos apresentados nas comunicações do XLI Seminário do GEL e no IX Encontro Nacional da ANPOLL trouxe polêmica. A pesquisa de caráter lexicológico e lexicográfico iniciada há cinco anos aproximadamente visa a desenvolver um estudo de importância para a área interdisciplinar entre Lexicologia, Lexicografia, Semiótica, Sociolingüística e Psicolingüística, já que nas duas apresentações em congressos se notou uma gama relevante de interesse interdisciplinar.

A árdua tarefa e a persistência de uma investigação profunda e verdadeira de se adentrar o inconsciente da mente humana permitiram uma estratégica pesquisa em busca dos dados lexicais intimamente preconceituados na mente dos falantes da comunidade lingüistica. Considerada a preconceituação ou "margi-nalização" um fenômeno que tem princípios éticos na estrutura de relações socio-culturais,

(*) Professor da Universidade de São Paulo. 
FERNANDES Jr. Alcebiades. O preconceito no uso do léxico. Língua e Literatura, n. 20 , p. $57-62,1992 / 1993$.

motivados por negligências dos valores instituídos por padrões ideológicos fundamentados na consciência do indivíduo, do grupo social ou da comunidade lingüística, devido aos conceitos ou preconceitos adquiridos por causas subjacentes a processos psíquicos ou ideológicos das experiências intrínsecas ou extrínsecas às relações socio-culturais, propôs-se, no primeiro trabalho, que o léxico tende a excluir as unidades lexicais que semanticamente refletem significados obscenos e imorais por força da "marginalização" objetiva da comunidade lingüística e, por outro lado, o léxico apresenta variação na macroestrutura ou nas microestruturas por efeito das "marginalizações" subjetivas produzidas pela comunidade lingüística, por grupos sociais ou pelo indivíduo, de modo que a "marginalização" de uma unidade lexical feita pela comunidade lingüística pode não ocorrer em um indivíduo ou em um grupo social e a "marginalização" feita por um indivíduo ou um grupo social pode ter sido produzida pela comunidade lingüística.

Com objetivos às causas subjacentes a processos psíquicos ou ideológicos, a pesquisa inicial apresentou numerosos problemas tantos quantas são as causas de preconceituação no uso do léxico. Após três investidas frustradas na investigação das unidades lexicais preconceituadas na consciência dos membros pertencentes a grupos da comunidade lingüística, a metodologia de pesquisa adquiriu uma nova característica: a rerrotulação do tema, a investigação indireta, a reformulação do instrumento de pesquisa.

A rerrotulação do tema da pesquisa tornou-se necessária pelo fato de que o termo "marginalização", em alguns casos, chegou a ofender o informante, nas pesquisas de grupos sociais, e a estimular críticas nas apresentações dos trabalhos nos congressos. Com isso, para a investigação de grupos sociais, o tema passou a "Pesquisa de Vocabulário" e para a primeira demonstração científica dos resultados obtidos, o título acima. Para a pesquisa em grupos sociais projetou-se um campo de diferentes áreas sociais. A investigação direta pelo pesquisador mostrou, nos dados coletados, uma inibição dos informantes, de modo que foi necessário selecionar e orientar para a pesquisa um indivíduo do gnupo social. A reformulação do instrumento de pesquisa foi gradativa: a presença do gravador inibia o informante; as numerosas perguntas do questionário dispersavam o objetivo da pesquisa; o preenchimento da ficha de pesquisa com o nome e o endereço do informante deixava-o comprometido. Daí, foi preciso elaborar um folheto com o tema, com as informações de idade, sexo e escolaridade e com a pergunta: "Cite uma palavra do nosso idioma que você se sente proibido ou constrangido em usá-la? Por que?" e dois envelopes com o timbre da Universidade de São Paulo, um para cada tipo de pesquisa ("individual" e "grupo"), em que os folhetos preenchidos e respondidos foram inseridos.

A pesquisa então passou a ter um objetivo prático: a) selecionar grupos sociais com diferentes atividades; b) comparar grupos de classes sociais distintas; d) distinguir, em cada grupo, sexo, idade e escolaridade (sem a identificação do informante); e) identificar o nível cultural nos grupos em observação às palavras 
proibido e constrangido expressas na questão do folheto; f) contrastar grupos e indivíduos em cada grupo social.

A seleção de grupos com atividades religiosas, escolares, profissionais, filantrópicas e recreativas da classe social alta e média-alta e da classe social baixa permitiu organizar a pesquisa com os "pesquisadores" (os indivíduos selecionados e orientados) dos grupos de atividade das classes sociais definidas: escolher no seu grupo de atividade 40 ou 20 indivíduos ( 20 adultos (10 homens e 10 mulheres (acima de 20 anos)) e/ou 20 crianças (10 meninos e 10 meninas com idade até 11 anos)), pedir que preenchessem o folheto e respondessem secretamente a questão do folheto, dobrando-o e colocando-o no envelope "individual" e lacrar o envelope em frente aos informantes; depois, escolher grupos de "amigos" e "amigas" na proporção numérica dos indivíduos, pedir que cada indivíduo do grupo preenchesse o folheto e respondesse secretamente a questão do folheto, dobrando-o e colocando-o no envelope "grupo" e lacrar o envelope frente aos informantes. O "pesquisador" foi orientado para aproximar do informante que não entendesse o significado da palavra constrangido e dissesse a ele, em particular, o significado, riscando a palavra, de modo que essa marca permitisse avaliar o nível cultural dos informantes. Definido o procedimento da pesquisa, instituiu-se um processo de avaliação com três parâmetros taxionômicos para a análise das unidades lexicais coletadas: obsceno, psicológico e ideológico. São unidades lexicais do tipo obsceno aquelas que expressam diretamente o significado obsceno ou que refletem todas em geral. As unidades lexicais do tipo ideológico são as unidades que refletem um significado coerente à ideologia da atividade do grupo social ou relativo à ideologia do sentido de humanidade. A distinção entre o obsceno, que é a "marginalização" no léxico produzida específica pela comunidade lingüística, e o ideológico, que é uma "marginalização" de unidades lexicais caracterizada pelo grupo social, são bem definidos na análise dos dados coletados. A análise das unidades lexicais do tipo psicológico, que é uma forma de preconceituação de unidades lexicais pelo indivíduo cujos significados refletem nele um conflito psicológico, não é muito bem definida, pois é necessário entender profundamente a justificativa dada pelo informante. Em alguns casos, as unidades lexicais do tipo psicológico confundemse com as características dos tipos obsceno e ideológico e, em outros, elas são bem marcantes na justificativa do indivíduo para o seu conflito intimo. $\mathrm{Na}$ verdade, essa tricotomia é apenas um recorte metodológico para uma avaliação dos dados coletados, porque, em qualquer unidade lexical preconceituada, há proporcionalmente os três traços com a predominância de um deles em maior grau, refletindo no indivíduo um desconforto ético-psicológico no uso da unidade lexical.

Os locais preferidos para a aplicação da pesquisa foram igrejas, escolas de $1^{\circ}$ grau e faculdades, empresas, sociedades filantrópicas e clubes. Para aplicação da pesquisa, estabeleceu-se uma distinção de classe social: locais de classe social alta ou média-alta (A) e locais de classe social baixa (B) com as mesmas atividades. Dentre eles, os clubes apresentaram problemas na pesquisa: os "pesquisadores" não conseguiram coleta de dados. 
O objetivo da pesquisa em analisar indivíduos e grupos de um grupo social com a mesma atividade implica verificar nos grupos se os individuos constituintes refletem uma forma de preconceituação peculiar do grupo ou do grupo social e verificar nos indivíduos, os que não pertencem aos grupos pesquisados, o parâmetro de preconceituação predominante no grupo social pesquisado.

\section{O resultado da pesquisa}

Embora essa pesquisa tenha iniciado há aproximadamente cinco anos, adentrando mais de 30 locais selecionados, poucas contribuições têm trazido excelentes resultados satisfatórios. Não é fácil invadir a privacidade do léxico armazenado na mente dos individuos. Essa nova metodologia de pesquisa tem sido bastante eficaz, colaborando muito com os resultados obtidos para o desenvolvimento desse trabalho.

Atualmente, com os $\mathbf{5 8 6}$ dados obtidos pela nova metodologia, apenas $\mathbf{3 0 6}$ são unidades lexicais qữe permitem uma avaliação, porque elas atendem a questão e a justificativa do folheto e o restante são unidades que não se ajustam ao objetivo da pesquisa: elas refletem uma figuração satírica e jocosa. Os locais que mais contribuiram para a pesquisa foram as igrejas e as escolas de $1^{\circ}$ grau.

A análise dos 306 dados trouxe informações interessantes para um estudo sobre a preconceituação no uso do léxico. Nas igrejas da classe $A$, os grupos (adultos masculinos e femininos e crianças masculinas e femininas), sem exceção, têm preconceitos por unidades lexicais do tipo obsceno e os indivíduos adultos masculinos e femininos têm preconceitos por unidades lexicais do tipo também obsceno e crianças masculinas têm preconceitos por unidades lexicais dos tipos obsceno e psicológico, constrastadas com crianças femininas que têm preconceitos por unidades lexicais do tipo ideológico. Nota-se que, na pesquisa do indivíduo, os indivíduos não apresentam influência de grupo e, na pesquisa de grupos, os individuos são influenciados pelo grupo. Nas igrejas da classe B, os grupos apresentam variação entre adultos e crianças masculinos que apresentam preconceitos por unidades lexicais do tipo obsceno e adultos e crianças femininos, por unidades lexicais do tipo psicológico; os indivíduos adultos masculinos apresentam proconceitos por unidades lexicais do tipo ideológico e adultos femininos e crianças masculinas e femininas, por unidades lexicais do tipo psicológico. Na pesquisa do indivíduo, os indivíduos também não apresentam influência de grupo. Nas igrejas da classe $\mathbf{A}$, os grupos não apresentam preconceitos por unidades lexicais do tipo psicológico e ideológico e os indivíduos crianças femininas não têm preconceitos por unidades lexicais do tipo psicológico. Nas igrejas da classe B, os indivíduos adultos masculinos e femininos não apresentam preconceitos por unidades lexicais do tipo obsceno. 
Nas escolas de $1^{\circ}$ grau da classe $\mathbf{A}$, os grupos de crianças masculinas e femininas e os indivíduos crianças masculinas apresentam preconceitos por unidades lexicais do tipo obsceno e ideológico e os indivíduos crianças femininas, por unidades lexicais do tipo psicológico e ideológico. Nas escolas de $1^{\circ}$ grau da classe $\mathbf{B}$, os grupos de crianças masculinas têm preconceitos por unidades lexicais do tipo obsceno e os de crianças femininas, em algumas escolas, por unidades lexicais do tipo obsceno e, em outras, por unidades lexicais do tipo psicológico e os indivíduos crianças masculinas e femininas apresentam preconceitos por unidades lexicais do tipo obsceno. Em certas escolas da classe A, os grupos de crianças femininas e os indivíduos crianças femininas não apresentam preconceitos por unidades lexicais do tipo obsceno.

Em empresas da classe $\mathbf{A}$, os grupos e os indivíduos adultos masculinos $\mathbf{e}$ femininos apresentam preconceitos por unidades lexicais do tipo psicológico. Os grupos de adultos femininos não têm preconceitos por unidades lexicais do tipo obsceno e ideológico e os indivíduos adultos masculinos, por unidades lexicais do tipo obsceno. Em empresas da classe $\mathbf{B}$, os grupos de adultos masculinos e femininos apresentam preconceitos por unidades lexicais do tipo psicológico e os indivíduos adultos masculinos, por unidades lexicais do tipo obsceno e os adultos femininos, por unidades lexicais do tipo psicológico. Os grupos de adultos masculinos e femininos não têm preconceitos por unidades lexicais do tipo obsceno e os indivíduos adultos femininos, por unidades lexicais do tipo ideológico.

Em sociedades filantrópicas da classe $\mathbf{A}$, os grupos de adultos masculinos apresentam preconceitos por unidades lexicais do tipo ideológico e de adultos femininos, as do tipo psicológico e os indivíduos adultos masculinos têm preconceitos por unidades lexicais do tipo psicológico e adultos femininos, as do tipo psicológico e ideológico. Os grupos adultos masculinos não apresentam preconceitos por unidades lexicais do tipo obsceno.

Em todos os locais de atividade pesquisados, a unidade lexical que é preconceituada tanto em grupos como em indivíduos, adultos e crianças (masculinos e femininos), com mais freqüência é a palavra "desgraça", que é considerada do tipo psicológico, seguida por outras do tipo obsceno.

Observou-se, nessa pesquisa, que os locais de classe social $\mathbf{A}$ apresentam um nível cultural mais elevado do que os locais de classe social $\mathbf{B}$, em observação à palavra constrangido insérta na questão do folheto de pesquisa.

Os pressupostos da pesquisa e o resultado da pesquisa de campo, com a unidade lexical "desgraça" a mais preconceituada no uso do léxico, e a unidade lexical "marginalização", incômoda no tema dos trabalhos apresentados, são significativos para esclarecer que a preconceituação existe e para o desenvolvimento da pesquisa, pois a aparente ingenuidade dos dois termos reflete no mais profundo da essência humana um surpreendente mistério na relação entre significante e significado, de certa forma, semelhante ao uso do signo na Idade Média, mas, com caracteristicas distintas de Século XX, já que nenhum deles apresenta, na sua referên- 
cia semântica, motivo para precon'ceituação de uso. Que relação semântica está implícita em cada unidade lexical na preconceituação do uso? Que interfere na relação entre significante e significado de cada unidade lexical diante da "ingênua" sinonímia do dicionário?

Parece que a preconceituação reside no uso figurado do léxico, por influência do ensino normativo da língua que tem como modelo o estilo literário próprio para a arte literária. Assim a comunicação quotidie tem-se tornado um pouco imprecisa para os invocados à inspiração poética, de modo que a preconceituação motivada por inferências socio-culturais torna-se inevitável.

Esses são portanto os primeiros resultados obtidos nessas coletas preliminares de uma grande pesquisa em desenvolvimento. Por isso, não se pode nesse momento apresentar uma conclusão definitiva na comparação dos dados coletados, porque qualquer afirmação apresentada aqui seria imatura diante de visão mais ampla e necessária para se estabelecer um julgamento das causas de preconceituação no uso do léxico, embora os dados apresentados contrastando classes sociais, sexo, idade, escolaridade e cultura mostrem subsídios para uma distinção analítica, mas pode-se admitir que os dados apresentados sejam relevantes para os interesses dos estudos interdisciplinares, principalmente aos que enfocam o "mito" nos estudos de Sociolingüística, Lexicologia, Lexicografia e Psicolingüística, conforme se pôde observar nos congressos.

\section{BIBLIOGRAFIA}

AEBISCHER, V. et alii (1991). "Falas masculinas, falas femininas?" Editora Brasiliense, São Paulo.

BARBOSA, M. A. (1981). "Léxico, produção e criatividade: processos de neologismo" Global, São Paulo.

GIRARDIN, C. (1979). "Contenu, usage social et interdits dans le dictionaire". In Langue Française, 43, Larousse, Paris.

MORTUREUX, M. F. (1974). “Analogie creatice formalle et sémantique”. In Langages, Didier-Larousse, Paris, (36): 20-33.

PICOCHE, J. (1977). "Précis de lexicologie française". Nathan, Paris.

\footnotetext{
ABSTRACT: This article shows the first concrete results from a lexicological and lexicographical research for an interdisciplinar study applied in social groups with the objective of confirming and elucidating the prejudices in lexical usage, which derive from an interference in the relationship between sign and meaning. Since the result presents "wease" lexical units, from a lexicological and lexicographical standpoint, the process development of prejudice in lexical usage is a phenomenon wich has ethial grounds on the structure of socio-cultural relations.
}

Key-Words: lexical usage, process, prejudices. 